\title{
Article \\ Impact of Synthetic Parameters on the Compressive Strength of Bagasse Ash-Clay Geopolymer
}

\author{
Noorul Amin ${ }^{1, *}$, Saeed Gul ${ }^{2}$, Sabiha Sultana ${ }^{3}$, Sultan Alam ${ }^{4}$ and Amir Naveed ${ }^{2}($ ) \\ 1 Department of Chemistry, Abdul Wali Khan University, Mardan 35000, Pakistan \\ 2 Department of Chemical Engineering, University of Engineering and Technology, Peshawar 25120, Pakistan; \\ saeed.gul@uetpeshawar.edu.pk (S.G.); amirkhattak@uetpeshawar.edu.pk (A.N.) \\ 3 Department of Chemistry, Islamia College University, Peshawar 25000, Pakistan; sabiha@icp.edu.pk \\ 4 Department of Chemistry, University of Malakand, Chakdara 18800, Pakistan; dr.sultanalam@yahoo.com \\ * Correspondence: noorulamin@awkum.edu.pk
}

Citation: Amin, N.; Gul, S.; Sultana, S.; Alam, S.; Naveed, A. Impact of Synthetic Parameters on the Compressive Strength of Bagasse Ash-Clay Geopolymer. Crystals 2021, 11, 937. https://doi.org/ $10.3390 /$ cryst11080937

Academic Editor: Vladislav V. Kharton

Received: 15 July 2021

Accepted: 29 July 2021

Published: 12 August 2021

Publisher's Note: MDPI stays neutral with regard to jurisdictional claims in published maps and institutional affiliations.

Copyright: (C) 2021 by the authors. Licensee MDPI, Basel, Switzerland. This article is an open access article distributed under the terms and conditions of the Creative Commons Attribution (CC BY) license (https:/ / creativecommons.org/licenses/by/ $4.0 /)$.

\begin{abstract}
The impact of different parameters on the compressive strength of geopolymer synthesized from clay and bagasse bottom ash is reported. Geopolymer was synthesized from thermally activated clay and bottom bagasse ash using sodium silicate and sodium hydroxide as activator. The maximum dissolution of alumina and silica from the bagasse ash and clay maintaining different alkali conditions is studied. The resulting geopolymer synthesized under different conditions is studied for compressive strength. Different characterizations of the resulting geopolymer were carried out using different analytical instruments. The results indicated that the dissolution and strength of geopolymer have close relationships with the alkali concentration, solution to solid ratio and curing period. The highest compressive strength of $25 \mathrm{MPa}$ was observed for $8 \mathrm{M} \mathrm{NaOH}, 24 \mathrm{MPa}$ for 0.3 solution to solid ratio, $30 \mathrm{MPa}$ for $60 \%$ clay and $30 \mathrm{MPa}$ for 27 days of compressive strength.
\end{abstract}

Keywords: bottom bagasse ash; activated clay; geopolymer; compressive strength; curing period; alkali concentration

\section{Introduction}

Geopolymers are three dimensional inorganic polymers with amorphous and some semi amorphous phases, having Si-O-Al linkage synthesized for the first time by Joseph Davidovit 1982. Geopolymers comprise a tetrahedral coordinate structure of $\mathrm{Si}^{4+}$ and $\mathrm{Al}^{3+}$ ions with oxygen as a bridge. Alkali metal cations like sodium $\left(\mathrm{Na}^{+}\right)$or potassium $\left(\mathrm{K}^{+}\right)$ balance the negative charges on $\mathrm{AlO}^{4-}$ [1]. The empirical formula of geopolymer may be as below;

$$
\mathrm{Mn}\left[-\left(\mathrm{SiO}_{2}\right) \mathrm{z}-\mathrm{AlO}_{2}-\right] \text { n. } \mathrm{wH}_{2} \mathrm{O}
$$

where (M) denotes alkali ions, (n) amount of poly-condensation, and (z) represents silica/alumina in molar ratio [2].

Geopolymer consists of mineral molecular chains bonded to each other with covalent bonding with various molecular units i.e., polysiloxo, polysialate, polysialate-siloxo and polysialate-disiloxo represented as (-Si-O-Si-O-), (-Si-O-Al-O-), (-Si-O-Al-O-Si-O-) and (-Si-O-Al-O-Si-O-Si-O), respectively [3].

Geo-polymerization is a synthetic reaction involving the reaction of minerals containing alumino-silicate and temperature in a strong basic medium [4], which is a complex process and the mechanism is not completely understood. The mechanism as proposed by Davidovits 1982 may involve the condensation polymerization of ortho sialiate ions 
(hypothetical monomers). The silica to alumina ratio may be one or sometimes greater than one. Three steps are involved in polymerization, comprised as follows;

$$
\begin{aligned}
& \left(\mathrm{S}_{i 2} \mathrm{O}_{5} \cdot \mathrm{A}_{l 2} \mathrm{O}_{2}\right)_{n}+n \mathrm{H}_{2} \mathrm{O} \stackrel{\mathrm{NaOH}}{\rightarrow}{ }_{n}(\mathrm{OH})_{3}-\mathrm{Si}-\mathrm{O}-\mathrm{Al}-(\mathrm{OH})_{3}
\end{aligned}
$$

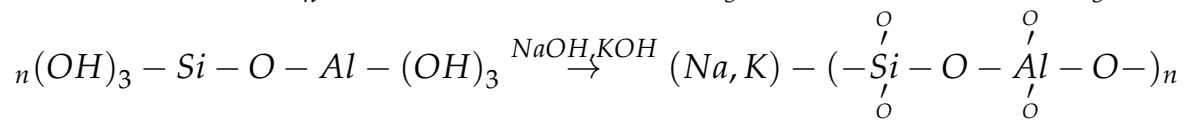

A geopolymer needs three basic components, in which the first one is a reactive alumino silicates source like bottom bagasse ash, meta-kaolin, rice husk ash etc., the second is filler material including thermally activated clay which is also a supplementary source of alumino silicate, and the third one is alkalis such as sodium or potassium hydroxide and their silicates [5]. Bottom bagasse ash is an ideal pozzolana containing ideal properties, which may be used for geopolymer and Portland cement production [6]. High strength geopolymer cement can be synthesized using bagasse ash and clay. Normally, sodium hydroxide and potassium hydroxide or silicates of sodium and potassium are used for geopolymerization. Dissolution of most of the minerals is higher in sodium hydroxide as compared to potassium hydroxide [7]. Moreover, sodium hydroxide demonstrates better resistance than potassium hydroxide towards acids [8]. Furthermore, due to the low cost of sodium hydroxide, geopolymer chemists encourage its use in the synthesis of geopolymers.

Amin et al. synthesized a geopolymer utilizing bottom bagasse ash and studied different parameters [9]. The strength of $50 \mathrm{MPa}$ has been reported using $10 \mathrm{M} \mathrm{NaOH}$ with a curing time of 28 days at $80^{\circ} \mathrm{C}$. Kaze et al. [10] explored the kinetic studies in geopolymerization reactions. It has been reported that the concentration of ions like $\mathrm{Si}^{4+}$ and $\mathrm{Al}^{3+}$ affects geopolymer properties. Amin et al. studied the fact that both silicon and aluminum are required for the development of geopolymer with a strong bonded structure. The strength of the geopolymer is influenced by the quantity of aluminosilicate combinations made, which is consecutively affected by the concentration of alkali, temperature, and alumino-silicates available in starting raw material. The relationship of ash fineness with the physico-mechanical properties of high calcium ash-based geopolymer was studied and reported [11]. Geopolymer mortar and concrete has also been synthesized by activating clay having high calcium with a mixture containing $15 \mathrm{M}$ sodium silicate and hydroxide [12], and 54.4 MPa strength was achieved at the curing period of 28. The strength was continually increased with the increase in curing time as that of Portland cement mortar and concrete. Zhang et al. [13] studied the curing conditions for the syntheses of the red mud-based geopolymer and found that the strength of the geopolymer rises with an increase in the ratio of both $\mathrm{Si} / \mathrm{Al}$ and $\mathrm{Na} / \mathrm{Al}$. Additionally, a lengthy curing period of up to 180 days was studied which showed a continuous strength increase. Various parameters for the preparation of slag-based geopolymer, including alkali/slag, water/geopolymer, alkaline/water were also studied for the development of maximum compressive strength [13]. He concluded that for excellent strength, concentration of alkali, composition of sodium silicate, ratio of silicate to hydroxide, temperature and curing time are the essential factors. The influence of alkalis, concentration of alkali and activated clay on compressive strength was studied and reported by Cheng et al. [14]. Greater unconstrained compressive strength in short-range curing time was achieved with $\mathrm{NaOH}$ and $\mathrm{Na}_{2} \mathrm{SiO}_{3}$ in the high curing period.

The present work is the synthesis and characterization of a geopolymer synthesized utilizing bottom bagasse ash and thermally activated clay, with ambient environments. The conditions optimized are concentration of alkali, content of alkali and activated clay and curing period. The mechanism of dissolution, strength development of geopolymer, and microstructural and mineralogical studies are studied and reported.

Both of the raw materials such as bagasse ash and clay are abundantly available with no price and their conversion to geopolymer in mixed form is a novel work. Moreover, changing and optimizing the synthetic parameters can result in the production of good 
quality geopolymer. The resulting geopolymer is a good alternative for the Portland cement in many applications such as construction material etc.

\section{Materials and Experiments}

\subsection{Raw Materials Characterization}

Clay was collected from Nowshera District, khyberpakhtunkhwa, Pakistan. Samples were first dried in the sun, and homogenized by mixing thoroughly. The samples were then dried in the oven at a temperature of $105^{\circ} \mathrm{C}$ for a period of $24 \mathrm{~h}$ and then stored separately in air tight containers for further study. The physical parameters of the starting raw materials are given in Table 1. Bottom bagasse ash was collected from premier sugar mill Mardan, Pakistan. The ash was pulverized in a mortar and pestle and stored in polythene bags for further studies. The chemical analysis of bagasse ash as studied using XRF is given in Table 1. Flakes of Pure Sodium hydroxide with as high a purity as $98 \%$ was purchased from the Merk chemicals and used as alkali activator. A solution of sodium hydroxide in the desired concentration was prepared $24 \mathrm{~h}$ prior to its use in order to ensure proper dissolution. The X-ray diffraction pattern of bagasse ash is given in Figure 1. The peaks indicate that bottom ash is composed of quartz and mullite. FTIR spectra of bottom bagasse ash and clay are shown in Figure 2, which shows the main characteristic bands. A peak at $1200-1300 \mathrm{~cm}^{-1}$ reveals the presence of $\mathrm{CaO}$ in clay, while the peaks in the range of $910-950 \mathrm{~cm}^{-1}$ are attributed to the siliceous content confirming that clay also contains some silicates. In bottom bagasse ash, the band at $1030 \mathrm{~cm}^{-1}$ represent the mullite phase while that at $1875 \mathrm{~cm}^{-1}$ confirms the presence of some water molecules.

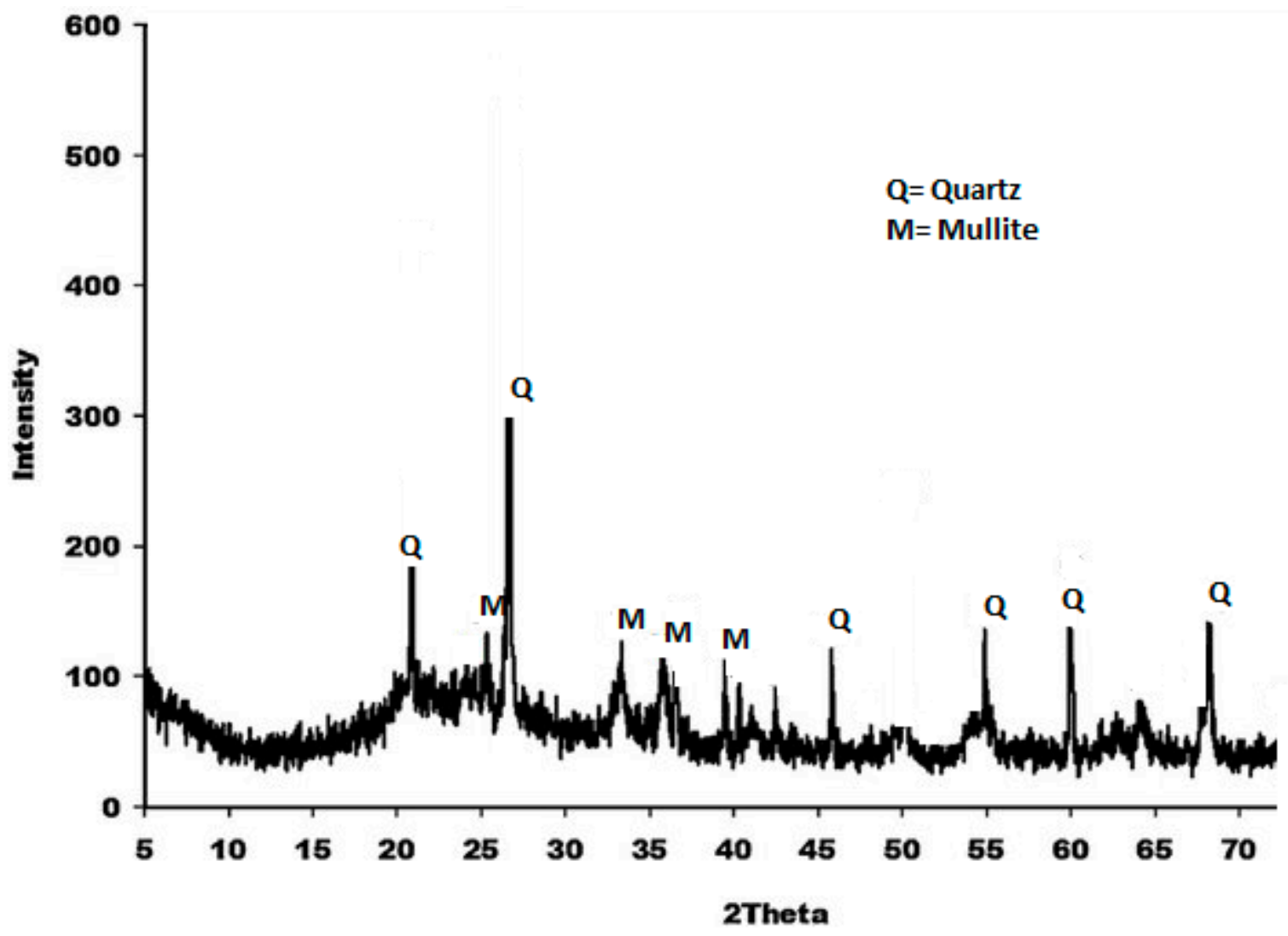

Figure 1. XRD pattern of bagasse ash. 
Table 1. Chemical composition of Bagasse ash and China clay.

\begin{tabular}{cccccccccc}
\hline & \multicolumn{9}{c}{$\mathbf{w t} \%$} \\
\cline { 2 - 10 } & $\mathbf{S i O}_{\mathbf{2}}$ & $\mathbf{A l}_{\mathbf{2}} \mathbf{O}_{\mathbf{3}}$ & $\mathbf{F e}_{\mathbf{2}} \mathbf{O}_{\mathbf{3}}$ & $\mathbf{C a O}$ & $\mathbf{M g O}$ & $\mathbf{N a}_{\mathbf{2}} \mathbf{O}$ & $\mathbf{K}_{\mathbf{2}} \mathbf{O}$ & $\mathbf{L O I}$ \\
\hline Bagasse ash & 78.046 & 3.813 & 2.012 & 3.975 & 2.245 & 0.211 & 0.421 & - \\
\hline Clay & 63.92 & 17.06 & 5.88 & 3.91 & 1.57 & 0.14 & 0.45 & 1.09 \\
\hline
\end{tabular}

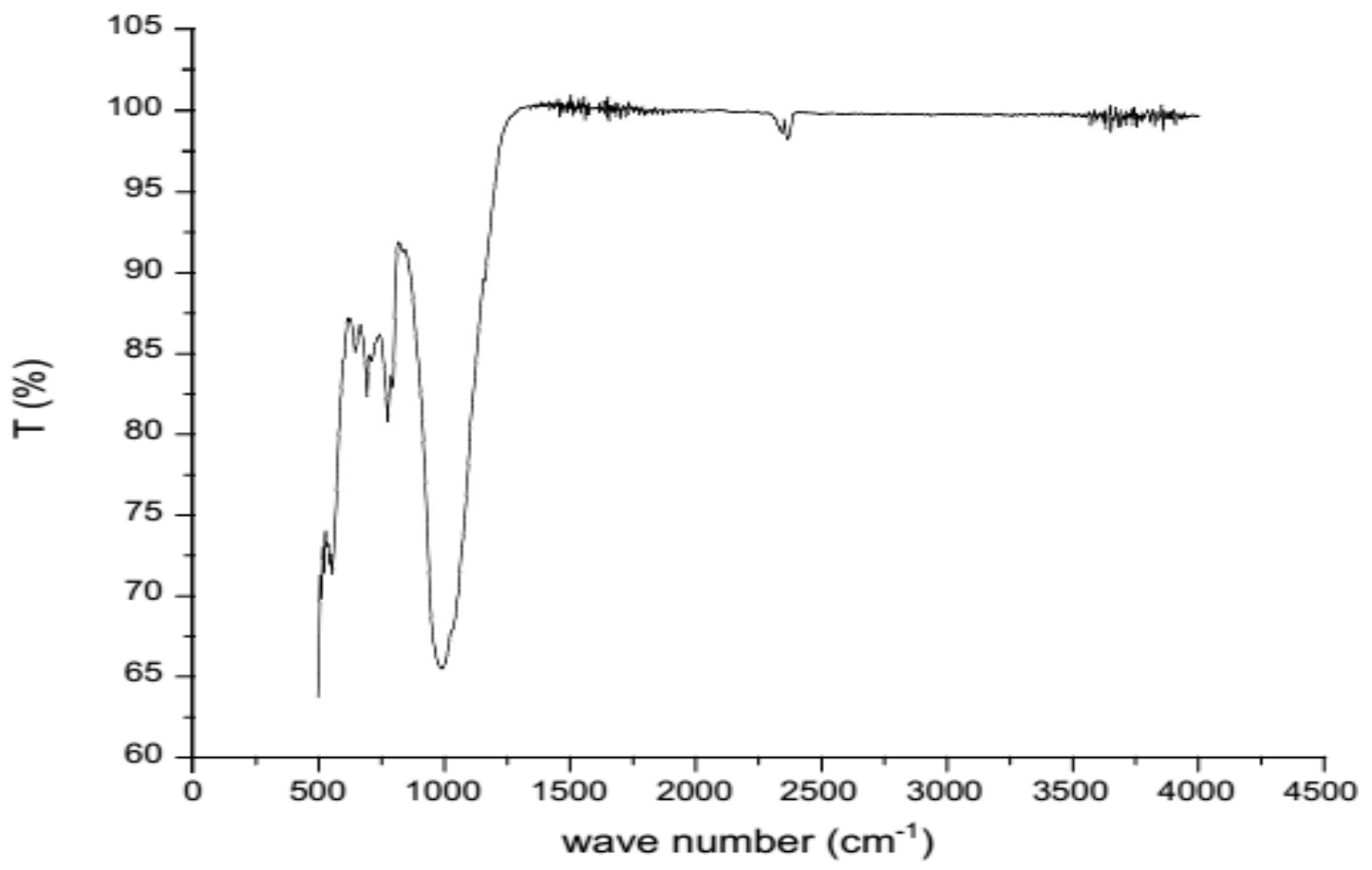

Figure 2. FTIR peaks of thermally activated clay.

\subsection{Experimental Program}

2.2.1. Dissolution of Alumino Silicate from Clay

Dissolved alumino silicate from the clay is different with a different alkaline medium using a Leaching test. For this purpose, $0.5 \mathrm{~g}$ of the thermally activated clay was dissolved in $50 \mathrm{~mL}$ of $\mathrm{NaOH}$. The concentration of $\mathrm{NaOH}$ was kept as 2, 4, 6, 8, 10, 12, 14 and $16 \mathrm{M}$. The mixture was stirred using a magnetic stirrer at $110 \mathrm{rpm}$ for $20 \mathrm{~min}$. The samples were then filtered using Whatman filter paper 40, and the filtrates were used for $\mathrm{Si}^{+4}$ and $\mathrm{Al}^{+3}$ ions. The amount of $\mathrm{Si}^{4+}$ and $\mathrm{Al}^{3+}$ in the filtrates were studied using Atomic Absorption Spectroscopy (AAS).

\subsubsection{Compressive Strength}

The clay was mixed with bottom bagasse ash in different ratios in the range of $0,20,40,60,80$ and $100 \%$ of activated clay and were named as $C_{0}, C_{20}, C_{40}, C_{60}, C_{80}$ and $\mathrm{C}_{100}$, respectively. Each blend was mixed with 2, 4, 8 and16 $\mathrm{M} \mathrm{NaOH}$, solution to solid ratio of $0.2,0.3,0.4$, and $0.5 \mathrm{ml} / \mathrm{g}$. The blends, after thorough mixing, were poured into PVC cylindrical molds and air voids were removed by vibrating the molds for $2 \mathrm{~min}$ using a vibrating machine. The specimens were demolded after $24 \mathrm{~h}$ of curing, and were kept covered with a plastic sheet to reduce evaporation. Samples of geopolymer were synthesized with various proportions of raw material, various alkali solution concentrations and various ratios of alkali solution to solid. The compressive strength of the whole synthesized geopolymer was studied at 3, 7 and 28 days using the procedure ASTM [15]. Three identical specimens were used for mix proportion, and the average of the three 
was considered as the compressive strength. All geopolymer specimens were synthesized, preserved and tested using ambient conditions.

\subsubsection{Mineralogical and Structural Analysis}

The mineralogical and structural study of the raw materials and synthesized geopolymer was made by an X-ray Diffractometer (XRD) with $\mathrm{Cu}$ Ka radiation at $40 \mathrm{~mA}$ and $40 \mathrm{kV}$ over the range of 5 to 60 at a scanning rate of $5 / \mathrm{min}$. The chemical bonds and structure of the material was studied by Fourier Transform Infra-Red (FTIR) Perkin Elmer Spectrum with a frequency range of $400-4000 \mathrm{~cm}^{-1}$. For this purpose, $13 \mathrm{~mm}$ diameter pellets were made by $\mathrm{KBr}$ pellet method. A $1 \mathrm{mg}$ sample was ground with $250 \mathrm{mg}$ of $\mathrm{KBr}$ and put into pellet form. The pellets were studied at $2 \mathrm{~cm}^{-1}$ resolution. For this study, broken pieces of geopolymer after compression strength were kept in ethanol in order to stop further reaction and were used. The ethanol-stored samples were then powdered to less than $75 \mathrm{~mm}$ size and then properly homogenized to obtain representative samples.

\section{Results and Discussion}

\subsection{Extent of $\mathrm{Si}^{4+}$ and $\mathrm{Al}^{3+}$ Ion Dissolution}

The dissolution of $\mathrm{Si}^{4+}$ and $\mathrm{Al}^{3+}$ from clay and bottom bagasse in sodium hydroxide solution with different concentrations is given in Figure 3. The dissolution of $\mathrm{Si}^{4+}$ and $\mathrm{Al}^{3+}$ occurs from alumino-silicate of the thermally activated clay and bagasse ash, which is drawn-out in the solution. It can be seen in the figure that the leaching of $\mathrm{Si}^{4+}$ and $\mathrm{Al}^{3+}$ is greater from bottom bagasse ash as compared to that of thermally activated clay, which may be attributed to the fact that bottom bagasse ash comprises a considerable extent of amorphous alumino silicates as compared to thermally activated clay, as is clear from Table 1. Figure 3 also shows that the maximum dissolution of $\mathrm{Si}^{4+}$ ions occurs at $8 \mathrm{M} \mathrm{NaOH}$ solution, i.e., $160 \mathrm{ppm}$ for clay and $260 \mathrm{ppm}$ for bagasse ash. Above 8M concentration of $\mathrm{NaOH}$, the dissolution again reduces, which is attributed to the rise in agglomeration of silica. Similar phenomena have been observed and reported by some researchers on the dissolution of ions from fly ash samples in alkaline media [11]. Another possible reason for the low dissolution of $\mathrm{Si}^{4+}$ at a higher alkali concentration is the low kinesis of ions from the ash and clay, which further arrests the leaching out of ions due to the thickening of the solution. The leaching of $\mathrm{Al}^{3+}$ ion at a given alkaline condition is considerably lesser as compared to that of $\mathrm{Si}^{4+}$ ion as is clear from Figure 3. The reason for this phenomenon is that both clay and ash have a lower concentration of $\mathrm{Al}^{3+}$ ion as compared to that of $\mathrm{Si}^{4+}$ ion as is clear from Table 1 . Furthermore, $\mathrm{Si}^{4+}$ ions have a greater dissolution characteristic than $\mathrm{Al}^{3+}$ ions [16]. Like $\mathrm{Si}^{4+}$ ion, $\mathrm{Al}^{3+}$ ions also show maximum concentration with $8 \mathrm{M}$ $\mathrm{NaOH}$, i.e., 25 and $35 \mathrm{ppm}$ in clay and bottom bagasse ash respectively. The difference in $\mathrm{Al}^{3+}$ concentration for bottom bagasse ash, and activated clay is smaller as compared to that of $\mathrm{Si}^{4+}$ which depends on the alumina contents in both the ash and clay (Table 1). 


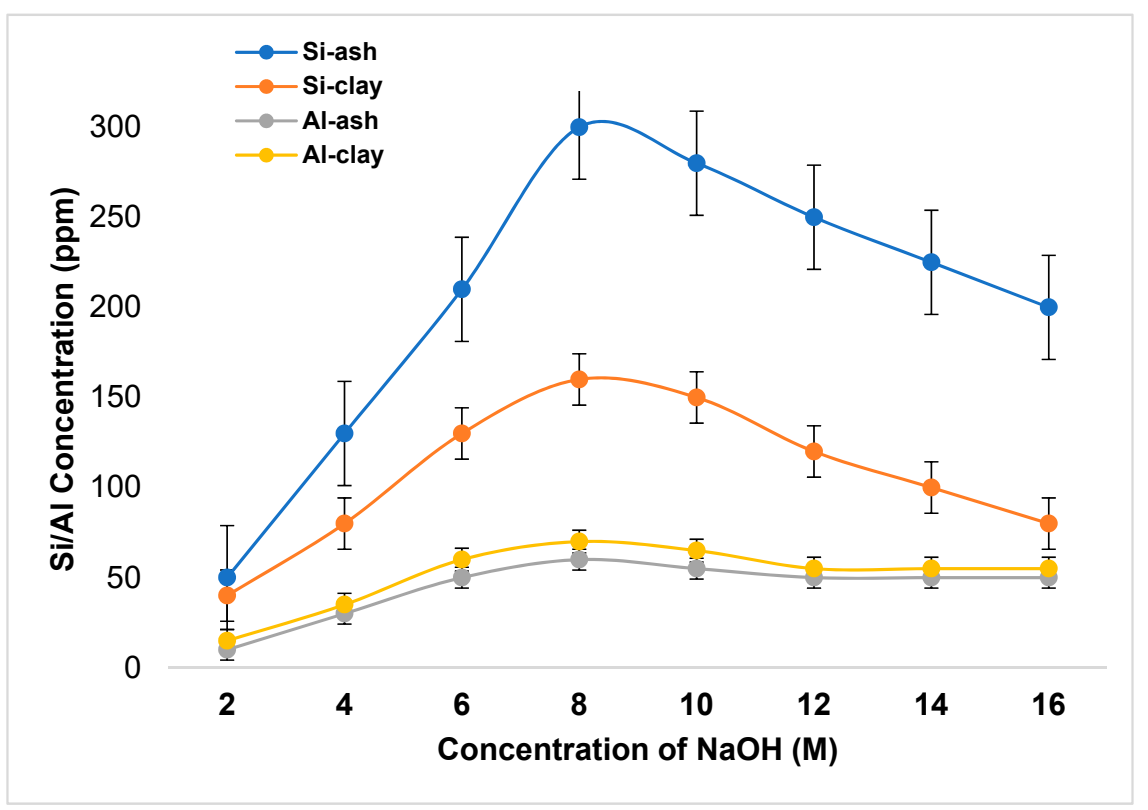

Figure 3. Effect of sodium hydroxide on the dissolution of silica and alumina.

\subsection{Effect of Different Parameters on the Compressive Strength}

\subsubsection{Effect of Alkali Concentration}

The concentration of sodium hydroxide has a crucial job in the getting high compressive strength. During our investigations, 28 days of compressive strength was examined with various concentrations of sodium hydroxide, and the results obtained are presented in Figure 4 . From the compressive strength results, it is very much clear that the concentration of sodium hydroxide is a significant factor influencing the strength accomplishment. Up to $8 \mathrm{M}$ concentration of sodium hydroxide, the strength expanded essentially, and afterward up to $12 \mathrm{M}$ a decline with further increment is observed. The conceivable clarification for this observation is that $\mathrm{OH}$ particles go about as impetus in synthetic response, which quickens the disintegration of alumino-silicate species and $\mathrm{Na}+$ particle goes about as charge adjusting cation in the grid [17]. At the point when the grouping of sodium hydroxide is low, lesser $\mathrm{Si}^{4+}$ and $\mathrm{Al}^{3+}$ particles disintegration occurs, which brought about the arrangement of a powerless polymeric system. This results in lower compressive strength. An optimum compressive strength is seen at $8 \mathrm{M} \mathrm{NaOH}$ fixation for all the bottom bagasse ash-clay blends. As the leachable $\mathrm{Si}^{4+}$ and $\mathrm{Al}^{3+}$ particles at $8 \mathrm{M} \mathrm{NaOH}$ are the greatest, which improves the poly-condensation procedure, it is normal that at $8 \mathrm{M} \mathrm{NaOH}$, the harmony between broken-up types of $\mathrm{Si}^{4+}$ and $\mathrm{Al}^{3+}$ particles and $\mathrm{Na}^{+}$particle is kept up. Subsequently, the most extreme compressive strength is acquired at that concentration. At a focus over $8 \mathrm{M}$, the draining of alumino-silicates may diminish or remain practically consistent, yet the convergence of free $\mathrm{NaOH}$ expands, which brings about a lower silicon to sodium proportion in the network which contrarily influences the poly-condensation procedure, and consequently the strength decreased [18]. 


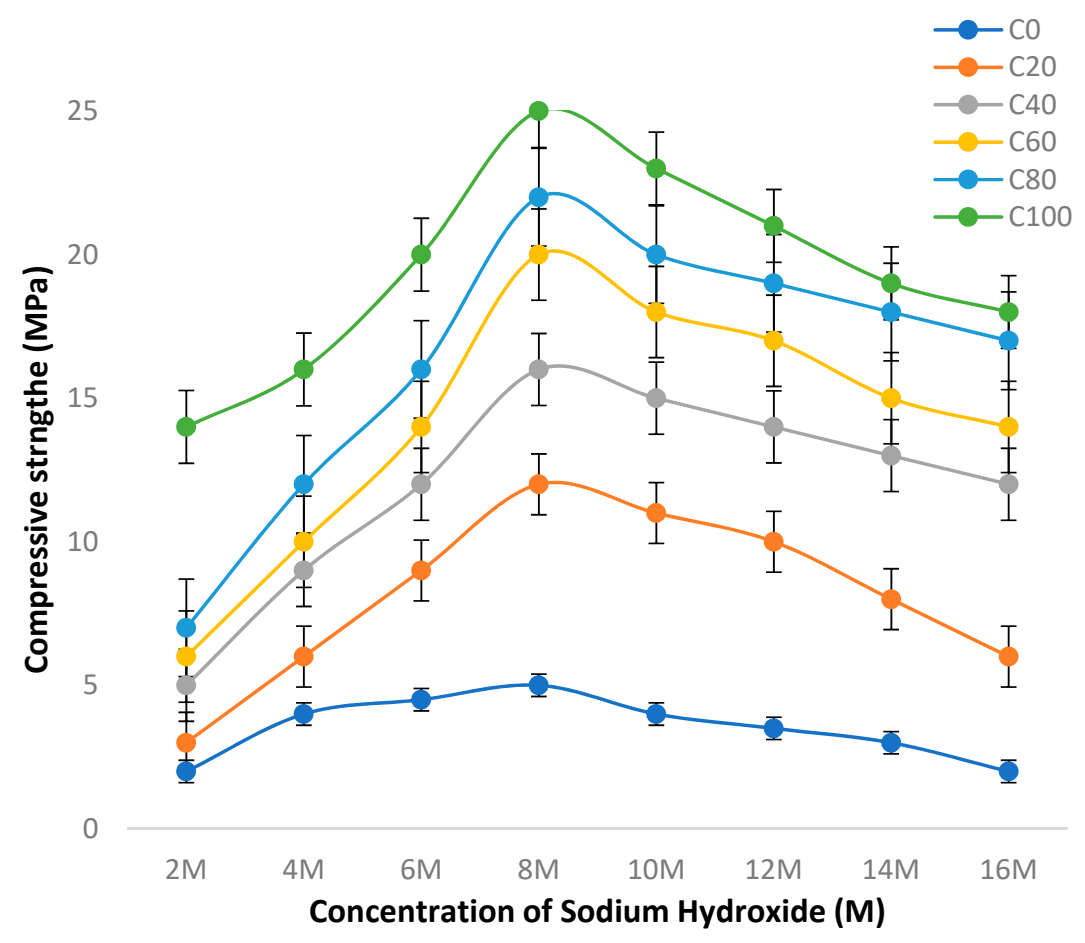

Figure 4. Effect of $\mathrm{NaOH}$ on the compressive strength.

\subsubsection{Effect of Solution to Solid Ratio}

The change of the compressive strength of the geopolymer with a change in ratio of solution to solid is given in Figure 5. For this experiment, the sodium hydroxide concentration used was $8 \mathrm{M}$, found to be the optimal concentration. It can be perceived from the figure that the strength of the geopolymer is influenced by solution and solid ratio in blend. For all the geopolymer samples at a specific ratio, the strength increases to a certain level and then an adverse effect is observed. The optimum ratio is $0.35 \mathrm{~mL} / \mathrm{g}$ as it gives maximum compressive strength. A large part of alumino-silicates is crystalline in bottom bagasse ash, whereas it is amorphous in thermally activated clay.

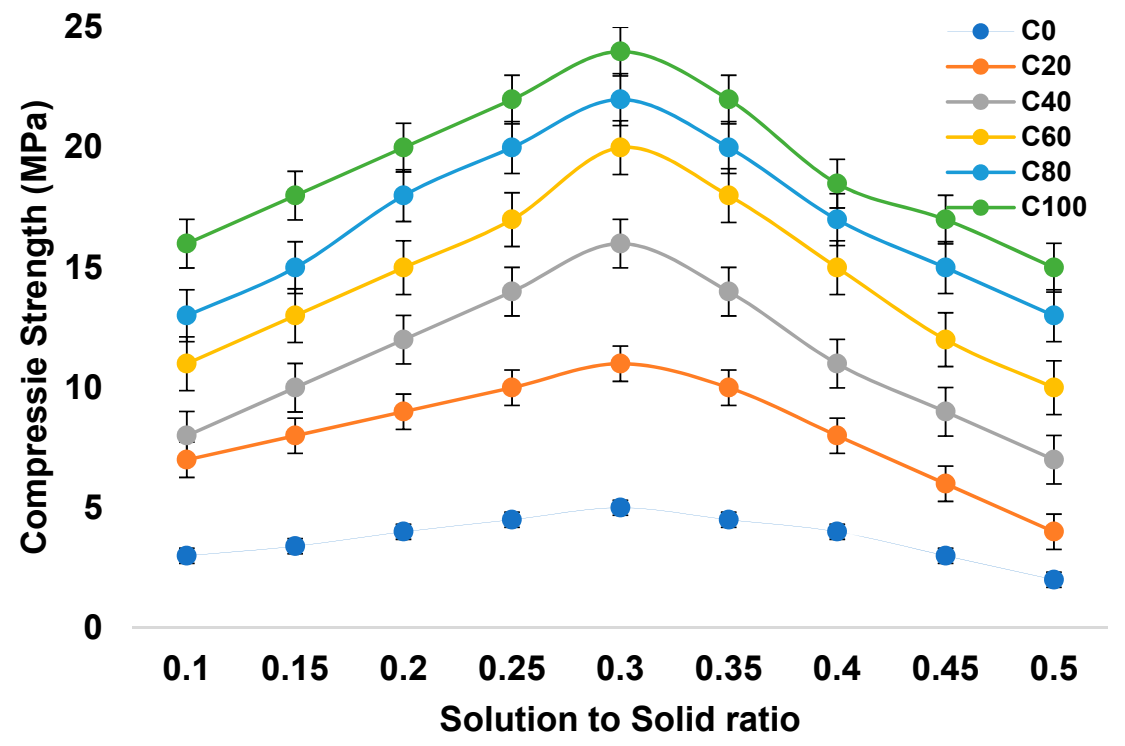

Figure 5. Effect of solution to solid ratio on the compressive strength of geopolymer. 
Alkali solution transfers soluble ions like $\mathrm{Si}^{4+}$ and $\mathrm{Al}^{3+}$ from bottom baggase ash and activated clay into aqueous phase by the dissolution process, which regulates the strength of a geopolymer $[13,15]$, so the amount of alkali used plays a key role in compressive strength improvement of the resulting geopolymer. If the amount of the alkali solution in the matrix is in a smaller quantity, it causes inadequate dissolution of solids, so a poor hydrolysis happens due to a lower solution to solid ratios. In the same way, for a greater ratio of solution to solid, increased dissolution occurs, embedding void spaces after hardening, which obstructs the mechanical veracity and therefore high strength is developed. It should be noted that an excess amount of sodium hydroxide leads to the creation of sodium carbonate as a result of the reaction of extra alkali and carbon dioxide from the atmosphere [19]. Therefore, both the excess/deficiency of alkali solution are not required as it drops the compressive strength. Moreover, excess amounts of $\mathrm{Na}^{+}$ions disrupt the balance of charge in the geopolymeric framework. the development of an alumino-silicate polymeric network is the result of poly-condensation, which releases water. There is an additional amount of water leftovers in the craters of structure which is utilized in the hydration reaction in samples of geopolymer samples containing rich activated clay. For samples of geopolymer containing bottom bagasse ash, the polymerization is comparatively slow due to the small discharge of alumino-silicates at normal environmental conditions. Hence, a drop in the compressive strength is detected at a greater ratio of solution/solid, because of the non-availability of an adequate amount of alumino-silicates and improved void spaces in the geopolymeric matrix due to additional molded water.

\subsubsection{Effect of Clay Content}

The quantity of thermally activated clay in the blend has been found to have extensive impact on the compressive strength of the geopolymer, which has been contemplated following 3, 7, and 28 days curing for all bagasse ash activated clay mixes with $8 \mathrm{M} \mathrm{NaOH}$ and solution to solid proportion of $0.35 \mathrm{~mL} / \mathrm{g}$ and the results are given in Figure 6. A rise in the content of activated clay in blend, causes a rise in the compressive strength. Greater content of the soluble alumino-silicate in alkaline media makes the process of poly-condensation more efficient which helps in the development of a high grade matrix. Therefore, a material with high compressive strength is achieved [19]. Thermally activated clay may comprise typically reactive alumino-silicates and the discharge of ions in alkaline state as compared to that of bottom bagasse ash. It was observed that the strength at 7 and 28 days of curing is increasing with increase in the content of activated clay in blend. Greater content of activated clay in the blend caused more accessibility of ionizable alumino silicates. Moreover, the availability of $\mathrm{CaO}$ in the activated clay recruits the hydration process, and consequently the compressive strength of $C_{100}$ is observed to be higher. Moreover, the $\mathrm{C}_{60}$ mix showed the highest strength instead of $\mathrm{C}_{100}$ for a curing age of 28 days. As for a longer period, the hydration reaction continued in the activated clay, it caused an unceasing dehydration in the geopolymer samples, which resulted in cracks in the specimens due to the shrinkage. Hence, up to a certain proportion of bagasse ash and thermally activated clay blend, enriched compressive strength is observed, and then a decrease in the strength is seen for further increase in the clay content. It is observed that the addition of bottom bagasse ash to activated clay, higher than $30 \%$, reduces the strength of geopolymer samples. 


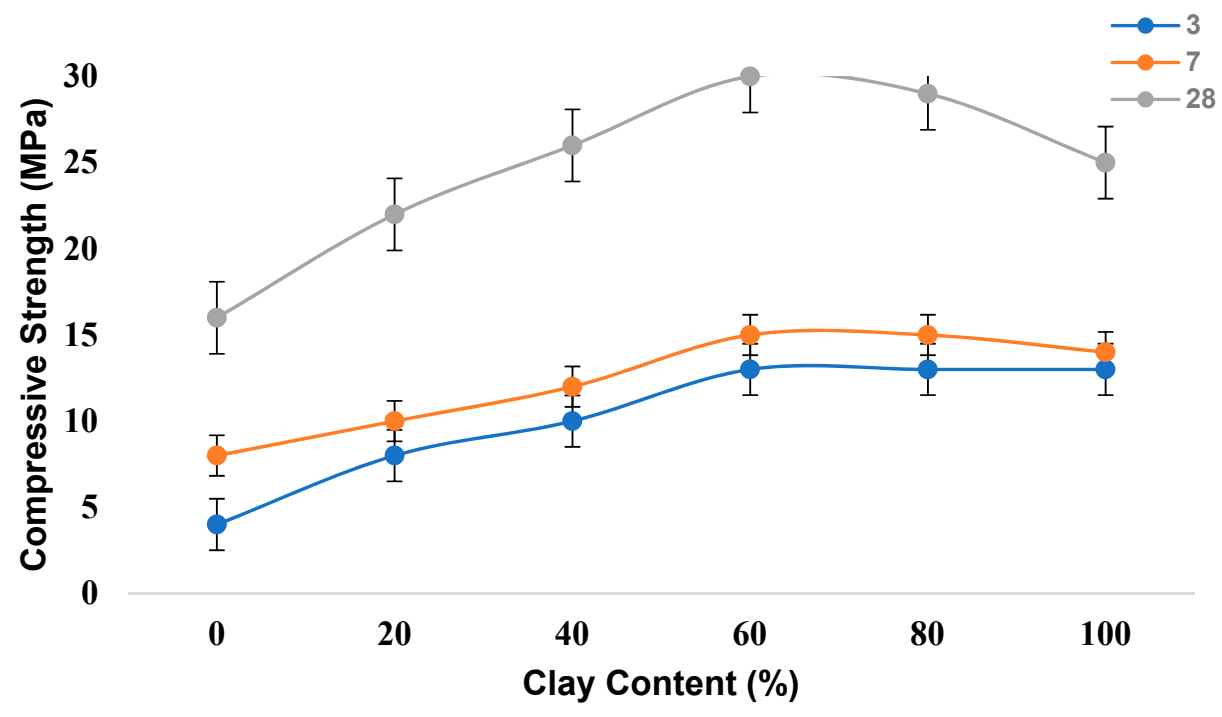

Figure 6. Effect of clay content on the compressive strength of geopolymer.

\subsubsection{Effect of Curing Period}

Compressive strength development of the geopolymer at various curing ages is shown in Figure 7. During these experiments, the concentration of sodium hydroxide and solution to solid ratio were kept as $8 \mathrm{M}$ and $0.35 \mathrm{~mL} / \mathrm{g}$, respectively, as these have been observed as the optimum condition. It is a common observation that curing time is an important parameter for the development of compressive strength. From the figure, it is clear that the relationship between increase in compressive strength and curing period exists almost linear except few samples having thermally activated clay. The compressive strengths of blends $\mathrm{C}_{60}$ and $\mathrm{C}_{100}$ become slightly stable after a curing of 7 days. Moreover, after a specific curing time, the samples rich with activated clay show greater compressive strength values as compared to samples having rich bottom bagasse ash. The rate of reaction for bottom bagasse ash is slow as compared to that of activated clay. The existence of minerals with calcium oxide in in clay supports a rapid setting which gives a rapid compressive strength. Similar observations have been reported by many researchers [20].

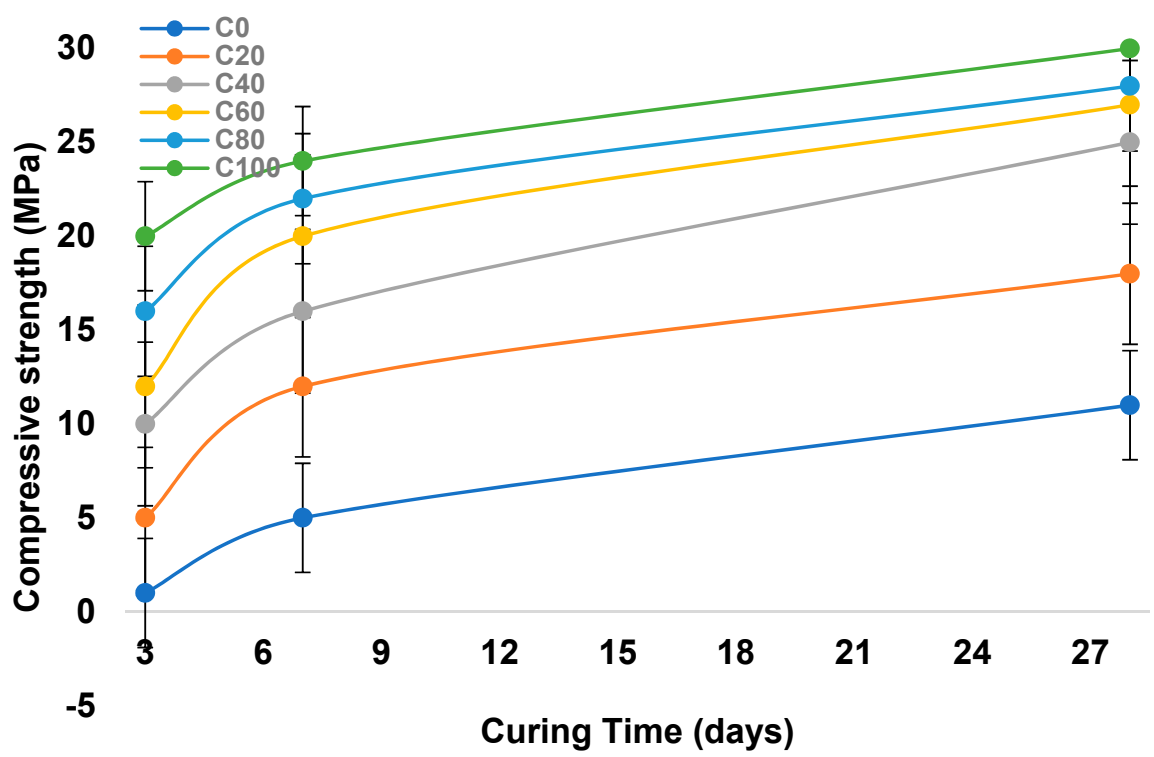

Figure 7. Effect of curing period on the compressive strength of geopolymer. 


\subsubsection{Confirmation of Chemical Bonds and Reaction Products}

The geopolymer product obtained from the reaction of bottom bagasse ash and thermally activated clay, using optimized conditions like $8 \mathrm{M} \mathrm{NaOH}$ solution and of $0.35 \mathrm{~mL} / \mathrm{g}$ solution to solid ratio, cured for 28 days are confirmed from the XRD patterns given in Figure 8. The figure shows that the main products obtained comprise calcium silicate hydrate, calcium aluminium silicate hydrate and calcite.

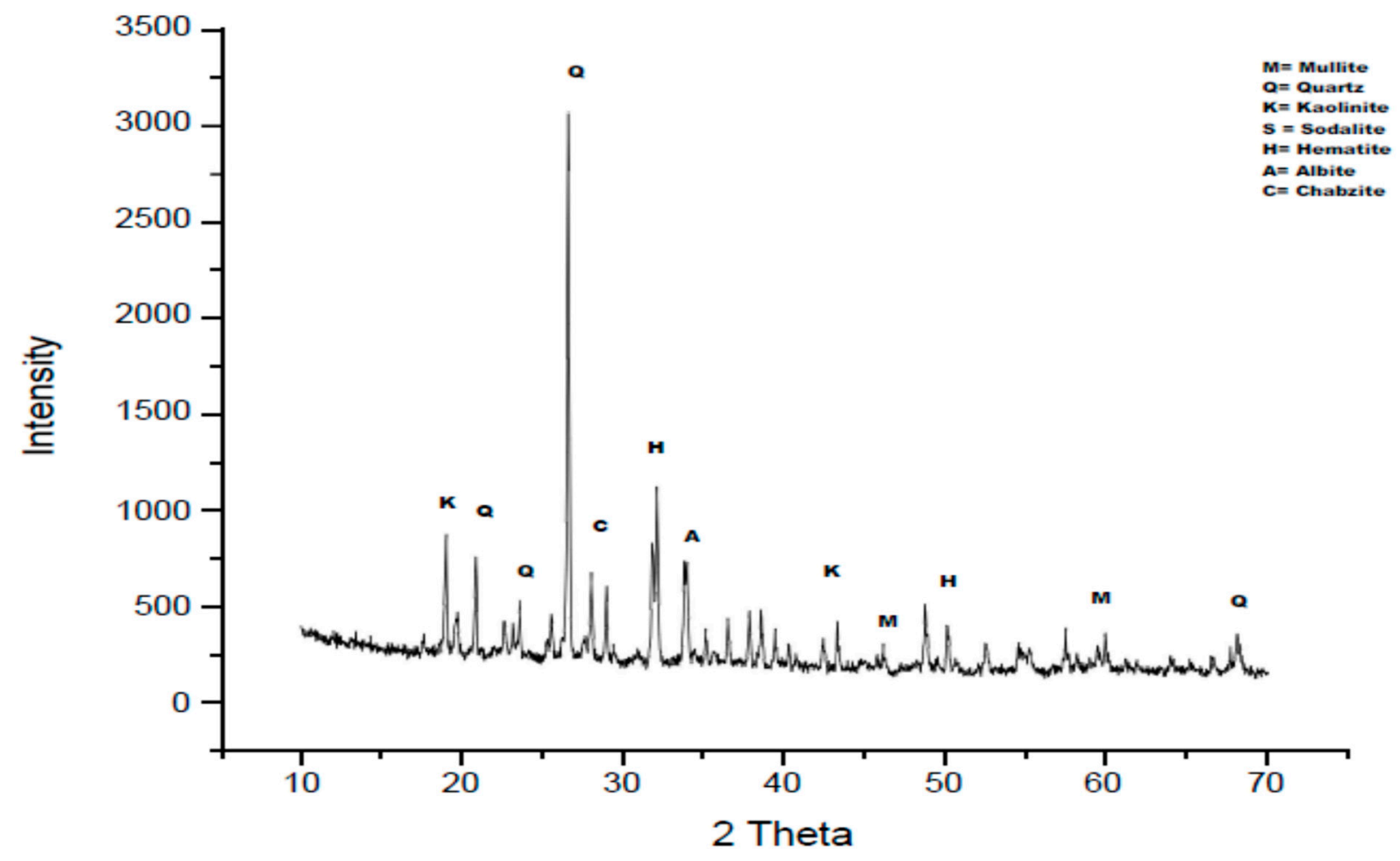

Figure 8. XRD pattern of geopolymer prepared at optimum conditions.

Characteristic peaks of mullite can be seen in bottom bagasse ash (Figure 1) and geopolymer (Figure 8), showing that these peaks remain unchanged during the reaction process. Other small peaks of sodalite, analcime and albite phase can be observed in geopolymer products. Meanwhile, the activated clay-based geopolymer shows large protuberance with extensive and dispersed peaks of semi-crystalline structures.

Figure 9 shows the FTIR spectra of the final product geopolymer prepared under the activated clay-bottom bagasse ash-based geopolymer. The spectra of source material and that of geopolymer products are different from one another by the nature and position of the peaks. The peaks at $685-898 \mathrm{~cm}^{-1}$ correspond to the symmetric stretching-vibration of Si-O-Al while those at 970 and $1087 \mathrm{~cm}^{-1}$ are due to the asymmetric stretching of Si-O-Si and Si-O-Al linkages. The silicates and alumino-silicates in the starting material such as bagasse ash and activated clay have contributed to the reaction causing the development of geopolymeric gel which may give high compressive strength, and this phenomenon can be concluded from the shifting of peaks in the raw material. The peaks at $1650-1800 \mathrm{~cm}^{-1}$ of the activated clay-based geopolymer show the existence of some bound water due to the bending vibration of $\mathrm{H}-\mathrm{O}-\mathrm{H}$. The peaks at $3700-3760 \mathrm{~cm}^{-1}$ may be because of stretching vibrations of $\mathrm{OH}$ groups, but the intensity of these peaks is very low in the starting material because there is no reaction product containing calcium- or sodium-based aluminosilicate in the geopolymer. 


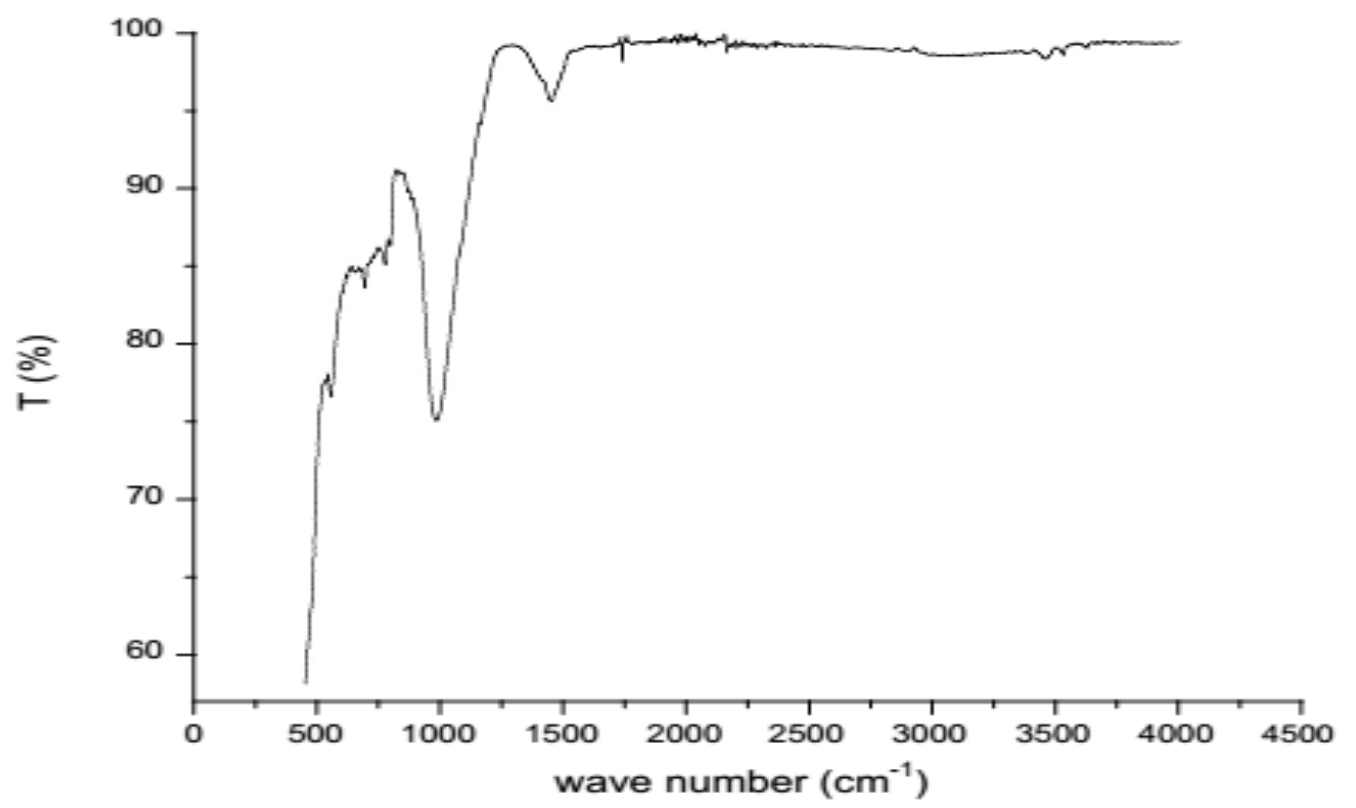

Figure 9. FTIR of the geopolymer obtained at the optimum conditions.

\section{Conclusions}

The effect of different synthetic parameters on the compressive strength of geopolymer was studied. The leaching mechanism of alumino-silicate ions from both bagasse ash and activated clay with different concentrations of sodium hydroxide was studied. It was found that the leaching of $\mathrm{Si}^{4+}$ and $\mathrm{Al}^{3+}$ ions from the raw materials depends on the concentration of the $\mathrm{NaOH}$ solution and the reactivity of raw material. The increase in compressive strength is observed up to $8 \mathrm{M} \mathrm{NaOH}$ and then shows a declining trend. Maximum compressive strength is achieved at a solution to solid ratio of 0.3 to $0.35 \mathrm{ml} / \mathrm{g}$. The compressive strength of geopolymer paste increases as the activated clay content in the bagasse ash-clay mix containing $60 \%$ activated clay. The reaction products in alkali-activated clay and bottom bagasse ash is different; calcium-based alumino-silicate hydration products are the major binding phase in alkali-activated activated clay with lesser amounts of geopolymeric products. Whereas, the amorphous sodium aluminosilicate is primarily found in alkali-activated bottom bagasse ash with minor amounts of hydration products.

Author Contributions: Basic concept and ideas, N.A.; Methodologies, N.A. and S.S.; Writing, S.A. and A.N.; Figures and Tables, S.G. and N.A.; Supervision, N.A. All authors have read and agreed to the published version of the manuscript.

Funding: This research received no external funding.

Conflicts of Interest: The authors declare no conflict of interest.

\section{References}

1. Alshaaer, M.; Abu Mallouh, S.; Al-Kafawein, J.; Al-Faiyz, Y.; Fahmy, T.; Kallel, A.; Rocha, F. Fabrication, microstructural and mechanical characterization of Luffa Cylindrical Fibre-Reinforced geopolymer composite. Appl. Clay Sci. 2017, 143, 125-133. [CrossRef]

2. Sellami, M.; Barre, M.; Toumi, M. Synthesis, thermal properties and electrical conductivity of phosphoric acid-based geopolymer with metakaolin. Appl. Clay Sci. 2019, 180, 105192. [CrossRef]

3. Andrejkovicova, S.; Sudagar, A.J.; Rocha, J.; Patinha, C.; Hajjaji, W.; da Silva, E.F.; Velosa, A.; Rocha, F. The effect of natural zeolite on microstructure, mechanical and heavy metals adsorption properties of metakaolin based geopolymers. Appl. Clay Sci. 2016, 126, 141-152. [CrossRef]

4. Phoo-Ngernkham, T.; Phiangphimai, C.; Damrongwiriyanupap, N.; Hanjitsuwan, S.; Thumrongvut, J.; Chindaprasirt, P. A Mix Design Procedure for Alkali-Activated High-Calcium Fly Ash Concrete Cured at Ambient Temperature. Adv. Mater. Sci. Eng. 2018, 2018, 1-13. [CrossRef] 
5. Tan, J.; Cai, J.; Li, X. Development of eco-friendly geopolymers with ground mixed recycled aggregates and slag. J. Clean. Prod. 2020, 256, 120369. [CrossRef]

6. Kara, I.; Yilmazer, D.; Akar, S.T. Metakaolin based geopolymer as an effective adsorbent for adsorption of zinc(II) and nickel(II) ions from aqueous solutions. Appl. Clay Sci. 2017, 139, 54-63. [CrossRef]

7. Furlani, E.; Maschio, S.; Magnan, M.; Aneggi, E.; Andreatta, F.; Lekka, M.; Lanzutti, A.; Fedrizzi, L. Synthesis and characterization of geopolymers containing blends of unprocessed steel slag and metakaolin: The role of slag particle size. Ceram. Int. 2018, 44 5226-5232. [CrossRef]

8. Gharzouni, A.; Joussein, E.; Samet, B.; Baklouti, S.; Rossignol, S. Effect of the reactivity of alkaline solution and metakaolin on geopolymer formation. J. Non Cryst. Solids 2015, 410, 127-134. [CrossRef]

9. He, K.; Chen, Y.; Tang, Z.; Hu, Y. Removal of heavy metal ions from aqueous solution by zeolite synthesized from fly ash. Environ. Sci. Pollut. Res. 2015, 23, 2778-2788. [CrossRef] [PubMed]

10. Kaze, R.; Moungam, L.B.; Djouka, M.F.; Nana, A.; Kamseu, E.; Melo, U.C.; Leonelli, C. The corrosion of kaolinite by iron minerals and the effects on geopolymerization. Appl. Clay Sci. 2017, 138, 48-62. [CrossRef]

11. Amin, N.U.; Nawab, L.; Ghani, U. Synthesis and characterization of chloride resistant cement from industrial waste through geopolymerization. J. Clean. Prod. 2017, 156, 577-580. [CrossRef]

12. Ji, Y.; Yang, H.; Yan, W. Strategies to Enhance the Catalytic Performance of ZSM-5 Zeolite in Hydrocarbon Cracking: A Review. Catalisys 2017, 7, 367. [CrossRef]

13. Zhang, Z.; Wang, H.; Zhu, Y.; Reid, A.; Provis, J.; Bullen, F. Using fly ash to partially substitute metakaolin in geopolymer synthesis. Appl. Clay Sci. 2014, 88-89, 194-201. [CrossRef]

14. Cheng, T.; Lee, M.; Ko, M.; Ueng, T.; Yang, S. The heavy metal adsorption characteristics on metakaolin-based geopolymer. Appl. Clay Sci. 2012, 56, 90-96. [CrossRef]

15. American Society for Testing and Materials. ASTM C618-08a. Standard specification for coal fly ash and raw or calcined natural pozzolan for use in concrete. ASTM Int. 2005. [CrossRef]

16. Mucsi, G.; Szenczi, Á.; Nagy, S. Fiber reinforced geopolymer from synergetic utilization of fly ash and waste tire. J. Clean. Prod. 2018, 178, 429-440. [CrossRef]

17. Ogundiran, M.B.; Kumar, S. Synthesis and characterisation of geopolymer from Nigerian Clay. Appl. Clay Sci. 2015, 108, 173-181. [CrossRef]

18. Cui, S.; Yu, S.; Lin, B.; Shen, X.; Gu, D. Preparation of $\mathrm{SiO}_{2}$ aerogel from rice husk ash. RSC Adv. 2015, 5, 65818-65826. [CrossRef]

19. Sagon, S.; Hunt, A.J.; Attard, T.M.; Mengchang, P.; Ngernyen, Y.; Supanchaiyamat, N. Valorisation of waste rice straw for the production of highly effective carbon based adsorbents for dyes removal. J. Clean. Prod. 2018, 172, 1128-1139. [CrossRef]

20. Amin, N.; Alam, S.; Gul, S. Assessment of pozzolanic activity of thermally activated clay and its impact on strength development in cement mortar. RSC Adv. 2015, 5, 6079-6084. [CrossRef] 